\title{
An Evaluation of Formative "In-Class" versus "E-Learning" Activities to Benefit Student Learning Outcomes in Biomedical Sciences
}

\author{
Rebecca Donkin and Elizabeth Askew \\ Discipline of Biomedical Sciences, University of the Sunshine Coast, Faculty of Sports, Health, Education and Engineering, \\ Sunshine Coast, Maroochydore DC, QLD, Australia \\ Correspondence should be addressed to Rebecca Donkin; rdonkin@usc.edu.au
}

Received 20 February 2017; Revised 6 July 2017; Accepted 3 August 2017; Published 13 September 2017

Academic Editor: Gary Velan

Copyright ( 2017 Rebecca Donkin and Elizabeth Askew. This is an open access article distributed under the Creative Commons Attribution License, which permits unrestricted use, distribution, and reproduction in any medium, provided the original work is properly cited.

\begin{abstract}
In conventional teaching, curriculum design that incorporates formative activities with prompt feedback is proven to have a positive effect on learning outcomes. Nevertheless, there is limited evidence that activities involving e-learning also have this positive effect and this is particularly the case within the discipline of hematopathology. The aim of this study was to evaluate the effectiveness of e-learning formative activities in hematopathology and to assess if, by using this resource, learning is enhanced. To address the research question, an e-learning module for anemia was developed to determine if it significantly increased knowledge, expressed by improved grades. Seventy-three students from health science programs that were enrolled in first-year hematology participated in the study. Students were encouraged to participate in two formative activities: one held in class and the other developed online as an e-learning module. Results showed a statistically significant increase in mean summative assessment score $(P=0.03)$ and final grade $(P=0.02)$ for students who completed the formative e-learning module. Interactive e-learning modules not only assist with engagement but also significantly improve grade outcomes. From this study, e-learning resources are an option for all educators but, in particular, those who have reduced face-to-face contact hours to teach the basic sciences.
\end{abstract}

\section{Introduction}

The ability to interpret clinical case based scenarios in hematology is a vital skill for students entering the pathology discipline of hematopathology (blood disorders). Understanding the testing procedures, interpreting results, and providing morphological reports are essential skills for the accurate diagnosis and treatment of patients with blood disorders. Although technology and automation in this clinical discipline have progressed over time [1], the basic human analytical skills required to interpret results remain unchanged. Interestingly, the modality of learning pathology skills has transformed curriculum design which has been influenced by the reduction in the number of face-to-face contact hours in basic science content and the decrease in teaching staff $[2,3]$. With the reduction in contact hours, a challenge exists to maintain relevant content whilst providing adequate practice to develop the necessary skills. Utilizing alternative teaching methods such as blended learning, simulation, or the flipped classroom provides an opportunity to maintain quality teaching standards and satisfy the demands of pedagogical change that is evidence based $[4,5]$. The growth of blended learning (a combination of face-to-face and online) and e-learning (using the Internet as a learning tool) has gained momentum in recent years $[6,7]$. These new teaching and learning methods can be accessed and experienced in a variety of ways through technology, computer-based classrooms, and anywhere/anytime accessibility to hand-held devices (virtual slides, projected imaging, mobile "apps," and interactive online modules). Online tools have superseded paper-based activities which were time consuming for the academic when providing individual feedback or when a physical presence in class was required in order to complete a paper copy [8-10]. The Millennial learner (born 1982-2004) has grown up in a technologically driven environment with a routine involvement with e-learning [11]. Advances in online 
or hand-held devices as learning tools have accommodated the individual learner's style and produces more meaningful and life-long learning in both a nonjudgmental environment and one that allows the user to work at their own pace $[12,13]$.

It is known that well-designed formative assessments can have a positive effect on engaging the learner in the biomedical sciences $[10,14]$ and the use of e-learning to impart knowledge acquisition and skills is an essential component of the 21st century educator. However, the appropriate educational tools that are freely accessible in hematopathology education are minimal [15]. Due to the promise and potential of innovative e-learning, our study investigated (i) the effectiveness of formative assessment to assess knowledge and skills in hematopathology with and without immediate online feedback prior to summative assessment and (ii) whether a new e-learning approach improves final grades.

\section{Materials and Methods}

2.1. Design Rationale. In previous years, the curriculum design at the authors institute for teaching erythrocyte disorders (anemia) consisted of "traditional" in-class summative paper-based case studies which depicted clinical scenarios of patients with signs and symptoms of anemia. Students were required to identify the typical presenting signs and symptoms, request appropriate tests, analyze test results, review a blood film by light microscopy, and provide a morphology report and a discussion on the pathophysiology and recommended treatment of the patient. There was no option to complete these tasks outside of class time, receive formative assessment with timely feedback, or have access to the equipment and staff resources beyond the allocated timetable. On the basis of student feedback, a need was recognized to (i) incorporate formative assessment in the teaching and learning process that provided timely and relevant support to assist in improved learning outcomes prior to the summative assessment and (ii) increase the opportunities for repetition and interactivity for the learner.

2.2. Formative and Summative Assessment. Currently (2016), students complete two formative and two summative case study tasks associated with the teaching of anemia. At completion of the modules, students receive two summative case study assessments. Task 1 incorporates a "traditional" style (no e-learning formative assessment) and Task 2 incorporates a "modern" style (e-learning formative assessment). Regardless of the lesson format, a case based approach that is familiar to the students is applied throughout each modality with formative assessment and feedback (prior to summative assessment). Both tasks assess the competency skills and knowledge attained throughout the course using clinical scenarios of patients presenting with anemia of unknown cause, simulating clinical practice.

The formative assessment associated with Task 1 (traditional case study assignment) was offered in class only. Students enrolled in one of five nonstreamed classes, facilitated by three tutors every week ( $1 \mathrm{hr} /$ week, for a total of eight weeks), with a student to tutor ratio of $15: 1$. To maintain similar experiences for all students, the tutorial content was exactly the same, irrespective of which tutor was involved or what class was taken. All students received a paperbased tutorial manual that contained the same resources and regardless of which tutor facilitated each week, they were given the same lesson plan. Tutorial resources included (i) a guide to completing a clinical hematology case; (ii) access to online virtual slides for morphology identification; (iii) short answer questions that included annotating virtual hematology slides; and (iv) an exemplar of a completed case study. The resource material and lesson plans were moderated by the course coordinator and course moderator to maintain clear course objectives and assessment outcomes to understand, identify, and critically analyze a clinical case of anemia. Feedback in class was dependent on the student completing the activity in the tutorial manual and seeking out the tutor for assistance, there was no option to include an elearning module or receive feedback outside of class time.

The formative assessment associated with Task 2 (case study exam) was offered as an online e-learning module. The online module consisted of the same resources as were supplied in class. However, they were available electronically and thus, multiple attempts could be made with the e-learning module outside of class, and the learner could work through the case study at their own pace and in their own time and receive immediate online feedback and directed access to further learning (Figure 1).

To observe any bias for academic ability between gender and enrolled program, a pretest hematology quiz consisting of multiple choice and short answer questions was conducted in week 1 of the course. To observe any further bias for self-selection, students were ranked in order by grade preand postsummative assessment to (a) identify if there were a comparable number of participants from both the upper and lower grade percentiles in each study group and (b) identify if a change in ranking occurred if students did, or did not, complete the formative activity.

2.3. Development of the E-Learning Module. The new elearning module associated with Task 2 was developed by the authors after reviewing evidenced based practice in elearning modules [15-17]. To ensure alignment with the curriculum outputs, the peer-reviewed module was linked to a clinical approach to anemia within the basic sciences, particularly relevant to the pathology profession. The Smart Sparrow Adaptive E-Learning Platform [18] was chosen as the software for developing the module because of the accessibility to various widgets; analytics component; instant feedback; adaptive pathways; and ease of use. Moreover, the published module can be deployed and viewed online (https://www.best.edu.au/) for adoption by other users. The module itself consists of a case based approach which incorporates interactive and engaging activities to learn a clinical approach to diagnosing anemia. The module comprises adaptive feedback; virtual slides; "drop and drag" morphology; multiple choice questions; "roll over" and annotated answers; extended feedback from a virtual "Biomedical Scientist"; and student-led learning (choice of activities). Figure 2 provides an example of an interactive "drop and drag" activity on a virtual blood film with incorrect feedback response but with 


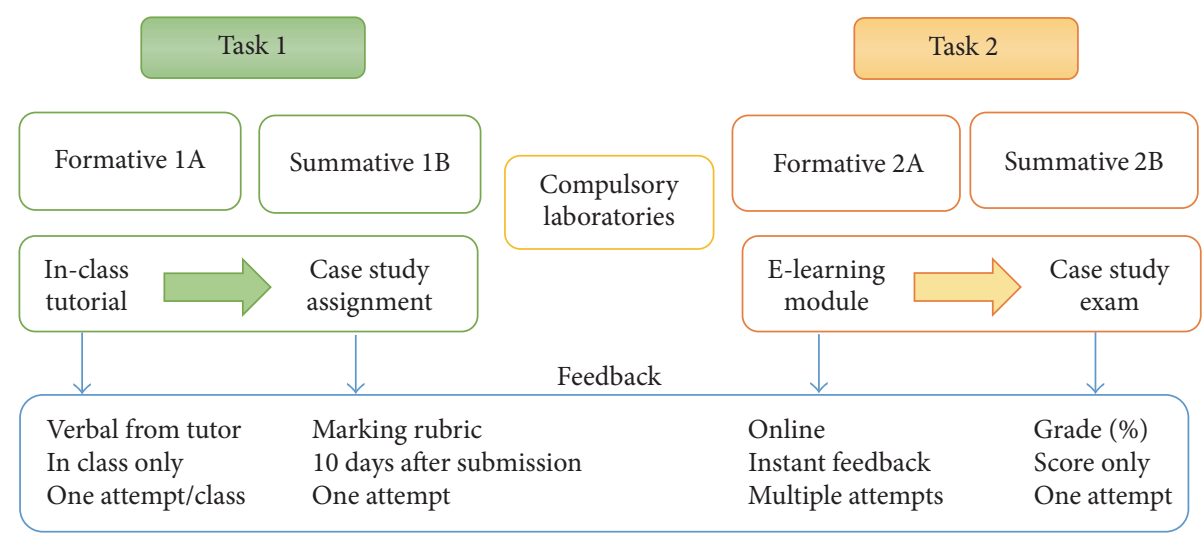

FIGURE 1: Flow chart demonstrating formative and summative task structure, including method of assessment and availability of feedback.

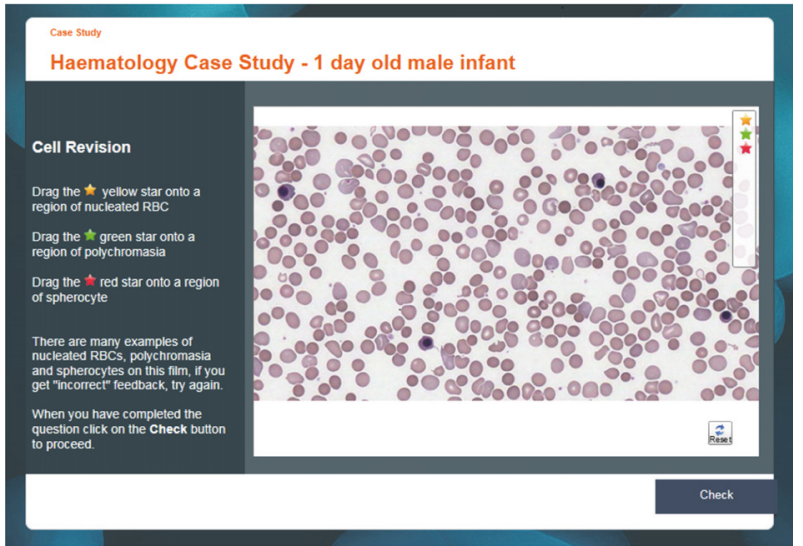

FIGURE 2: Example of an interactive "drop and drag" activity in the elearning module. The learner can interact with the activity by using the cursor to drag the appropriate star to a region of interest on the blood film and then receive instant feedback regarding their choices. After three incorrect attempts the module highlights the correct answer with feedback and directed learning, providing the learner with a choice to proceed or review further material. Analytics are available to the academic to monitor each question and answer and adapt the question or activity to suit the learner.

the capacity to complete multiple attempts. In keeping with the goals of developing online e-learning lessons, the module was designed to be completed by the learner in no more than 30 minutes, reducing overdetailed and high volume content, which may distract from the core learning objectives.

2.4. Statistical Analysis. Quantitative data from the tasks and the descriptive statistics were analyzed using the Statistical Package for Social Sciences (SPSS) version 22 (SPSS Inc., Chicago, IL). Data were analyzed using independent sample $t$-tests with criteria of a 95\% confidence interval and a null hypothesis that there is no significant change in student's grade following participation in a formative e-learning module. A $P$ value $<0.05$ was a significant level to suggest strong evidence against the null hypothesis.
2.5. Evaluating Efficacy with Statistical Power. In order to show a $25 \%$ difference between groups with statistical power $>95 \%$, a sample size of at least 15 students per group was required.

\section{Results}

Seventy-three students from health science programs enrolled in first-year hematology participated in the study. Approximately two-thirds of the participants were female and three-quarters were enrolled in a medical science program. The students enrolled as a course elective were from backgrounds in law, social sciences, or premedicine. There were no prerequisite courses required to enroll in this first-year course nor were there any requirements for prior knowledge or remedial classes linked to commencement: all students began the course with the same hematology baseline knowledge. To exclude any bias for academic ability between gender and enrolled program, a pretest hematology quiz consisting of multiple choice and short answer questions was conducted in week 1 of the course. The average mark for the pretest result was $85 \%( \pm$ SD 12.58$)$; there was no statistically significant difference between the gender $(P=0.107)$ and the program $(P=0.161)$. The pretest quiz result $(\% \pm \mathrm{SD})$ by gender and enrolled program is presented in Table 1.

As the formative activities were not graded, students self-selected whether they would complete one or more of the formative activities and identified themselves as either "completed formative activity" or "did not complete formative activity" associated with each summative task. Table 2 identifies the participants who completed the formative activities.

Of the 73 students in the study, 48 (66\%) participated in formative activity $1 \mathrm{~A}$ and 16 (22\%) participated in formative activity $2 \mathrm{~A}$. The average class grade for Task 1 was $73.16 \%$ ( \pm SD 19.55) and for Task 2 was 59.42\% ( \pm SD 23.67). The difference in mean result for summative tasks is illustrated in Figure 3.

Students who completed the formative activity associated with Task 1 showed an apparent improvement in grade 
TABLE 1: Participant characteristics by gender and program.

\begin{tabular}{lcc}
\hline Background variables & Number of participants $(\%)$ & Pretest quiz result \% $( \pm$ SD) \\
\hline Gender & & \\
$\quad$ Female & $45(62)$ & $86.40( \pm 10.93)$ \\
$\quad$ Male & $28(38)$ & $82.60( \pm 14.93)$ \\
Enrolled program & & \\
Biomedical Science & $32(44)$ & $86.50( \pm 10.09)$ \\
Medical Laboratory Science & $22(30)$ & $84.47( \pm 15.45)$ \\
Other (course elective) & $19(26)$ & $83.16( \pm 13.35)$ \\
\hline
\end{tabular}

TABLE 2: Completion of formative (nonassessable) tasks.

\begin{tabular}{lccc}
\hline Case study task & Number of participants (\%) & Gender (\%) & Program (\%) \\
\hline Activity 1A: in class only & $48(66)$ & $\begin{array}{c}\text { Female 29 (60) } \\
\text { Male 19 (40) }\end{array}$ & $\begin{array}{c}\text { Biomedical Science 18 (38) } \\
\text { Medical Laboratory Science 13 (27) } \\
\text { Other-course elective 17 (35) }\end{array}$ \\
\hline Activity 2A: E-learning module & $16(22)$ & $\begin{array}{c}\text { Female 9 (56) } \\
\text { Male 7 (44) }\end{array}$ & $\begin{array}{c}\text { Biomedical Science 4 (25) } \\
\text { Medical Laboratory Science 7 (44) } \\
\text { Other-course elective 5 (31) }\end{array}$ \\
\hline
\end{tabular}

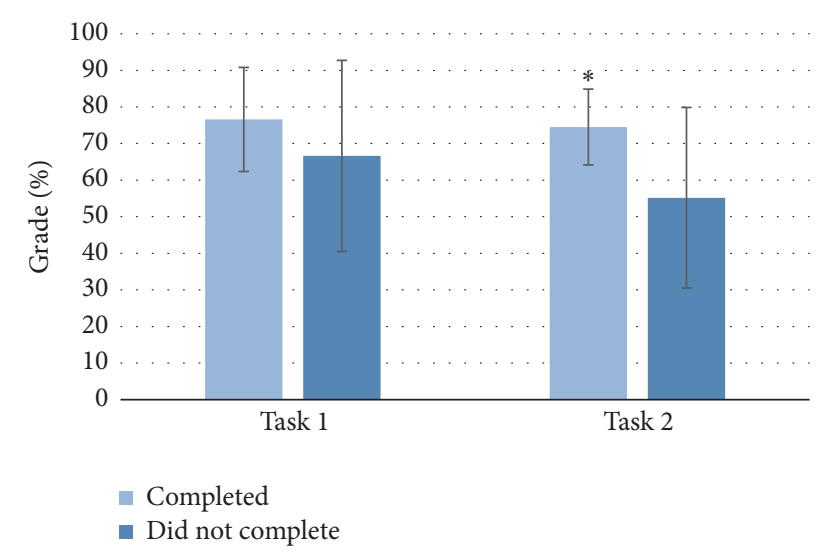

FIGURE 3: Summative task results between students who did "complete" and those that "did not complete" the formative case study activities. Students who completed the e-learning formative activity had an improved Task 2 grade that was statistically significant* .

(76.58\% \pm SD 14.22) versus those that did not complete the activity $(66.60 \% \pm \mathrm{SD} 26.12)$ but this was not statistically significant, whereas those who completed the e-learning formative activity associated with Task 2 had an improved grade $(74.50 \pm S D 10.36)$ that was statistically significant from those that did not complete the formative activity (55.19 \pm SD 24.66). There was a trend for increased score for students who completed the formative task associated with the summative assessment (Task 1). However, there were statistically significant results* for increased score for those students who completed the formative e-learning module associated with Task 2 exam and final grade score (Table 3).

Students ranked in order by grade presummative task showed no significant difference in pretest scores whether they did or did not self-select a formative activity; this suggested an even distribution of students across each group.
However, students ranked according to postsummative tasks showed significant improvement by higher rank if they had completed the formative e-learning module. These students moved up in position ranking by an average of nine places ( \pm SD 19). Students who did not complete the e-learning module had a mean rank change of zero $( \pm$ SD 21$)$. There was no significant difference in final grade when comparing program enrolment or gender.

\section{Discussion}

The data collected during our study indicates that an elearning module that provides an engaging way to learn hematology case studies together with immediate feedback on student performance has a significant positive effect on grade outcome. Students that completed the formative activities were likely to improve their grade for the summative task and improve their overall grade ranking position. There was a propensity that those students who participate in only one formative activity also benefit from feedback and an opportunity to practice and refine learning skills.

4.1. Implications for Learning Practice. There is a need to reform the curriculum in biomedical science to engage students who are disinterested in their studies. Many biomedical science students view science as hard, boring, or uninterestingly presented [19]. Adaptive e-learning is expected to address the changing needs of the current and future generations of students [20] as well as allow teachers to identify problem areas and difficult concepts using the real-time analytics and subsequently adapt and improve their lessons.

Adaptive e-learning described in this study provides, through technology, instructional content that adapts to learners' needs or desires [21]. It has the ability to provide the learner with adaptive feedback via numerous pathways that can be immediate and can target a learner's specific action and 
TABLE 3: Statistical differences in mean grade between students who did and did not complete formative case study activities.

\begin{tabular}{lccr}
\hline & $\begin{array}{c}\text { Completed formative activity } \\
\text { Mean grade\% }( \pm \mathrm{SD})\end{array}$ & $\begin{array}{c}\text { Did not complete formative activity } \\
\text { Mean grade\% }( \pm \mathrm{SD})\end{array}$ & $\begin{array}{c}T \text {-score } \\
P \text { value }\end{array}$ \\
\hline Task 1 & $76.58 \pm 14.22$ & $66.60 \pm 26.12$ & 0.09 \\
Task 2 & $74.50 \pm 10.36$ & $55.19 \pm 24.66$ & 3.8 \\
Final grade & $79.25 \pm 8.62$ & $64.81 \pm 23.02$ & $0.03^{*}$ \\
\hline
\end{tabular}

provide an interactive and personalized learning experience. As recorded in the literature [22], formative activities that provide timely feedback and an opportunity for repetition of core knowledge and fundamental skills with clinical application are good predictors for improved performance in summative assessments and final grades. Our results demonstrated that a significant improvement in mean grades can be achieved when completing a formative e-learning module to learn and practice before grade assessment.

4.2. Development and Design of E-Learning Modules. The design of modules that incorporate instant feedback is one of many attributes of the e-learning module. E-learning engages the student by using a "hands-on" approach that allows the learner to be self-paced and self-led and this improves engagement and understanding. This is likely to influence retention of knowledge and increase exam performance [23]. Appropriately these designed modules can also simulate a real-world experience in a profession.

From the perspectives of the authors of this paper and evidenced based literature $[17,24-26]$, the design of an interactive and adaptive e-learning module should demonstrate the purpose and academic value of twelve key aspects:

(i) providing comprehensive learning objectives;

(ii) stimulating attention, engagement, and motivation to continue the module;

(iii) containing knowledge that reduces cognitive load;

(iv) using time in an efficient way;

(v) giving the ability to complete and repeat the module anywhere/anytime;

(vi) offering positive interactive experience;

(vii) demonstrating good aesthetics of the interface and user friendly design;

(viii) providing instant feedback and evaluation;

(ix) adaptable self-led learning;

(x) choice of learning pathway;

(xi) immediate analytics for improved usability and learning modification;

(xii) an application of the module to "real-world" scenarios.

Design of new e-learning modules in the human pathology field requires encouragement of students to participate and proof of the modules effectiveness. Asking students to participate in nonassessed formative activities, which make no contribution to their academic grade, may not attract the student. Some students prefer traditional learning methods in preference to online learning although this may reflect the design quality or usability of the resource [27]. The elearning module should be designed to enhance rather than replace the "real-world" experience. Not all students learn at the same pace or adapt to the technology provided and a blended learning model that allows face-to-face contact remains important [28]. Science students have been shown to better understand diagnostic outcomes related to clinical application when they are actively involved in learning [17]. Therefore, classes that reinforce concepts and expose students to the learning material in a practical environment are likely to maximize learning outcomes.

4.3. Limitations. Despite the positive evidence for engagement and the drive to develop and implement e-learning, the production of e-learning modules is often time consuming: the module described in this study took $80+$ hours to develop content, test within the student cohort, verify content with experts in the field, review changes from student and expert feedback, and disseminate it to the learner. Educators and clinicians may not have the time, resources, or the technical expertise to develop e-learning modules [24]. Ongoing support for the development and sustained implementation is required to produce educational resources that have been developed using evidence based practice.

Establishing a relationship between participation and performance through the adoption of formative activities may require encouragement to participate. It is likely that the highly motivated learner will always participate in the formative activities [14] but the majority of students will require an incentive or a justification of their time to complete the activity and a clear indication of the benefit to their academic outcome. Although our study had a lower than expected participation rate, there was an even distribution of both high and low grade rankings in each group and furthermore, there was no statistically significant bias regarding background variables of gender or enrolled program.

Further important research questions involve reproducibility of the results and measuring how well students retain the information presented using formative means and if the case studies continue to be relevant after university when the graduates enter the clinical profession.

\section{Conclusions}

This study concurs with the notion that formative assessment has a positive impact on student learning. Interactive and 
engaging e-learning modules not only assist with knowledge and comprehension but also significantly improve grade outcomes. Further research is needed into the development of elearning modules in hematopathology and other biomedical sciences to assist learning.

\section{Conflicts of Interest}

There were no conflicts of interest the authors were aware of when completing this manuscript.

\section{Acknowledgments}

The authors would like to thank the teaching and technical staff in hematology, in particular Dr. Lin Fung and Mr. Geoff Simon, for assisting students with their in-class learning and peer-review of the teaching material. They would also like to thank the support staff from Smart Sparrow and Best Network, especially, Dr. Danni Cheng for her assistance with deploying the e-learning module and Professor Richard Burns for support with academic communication. This study was funded in part by an Enhancement Learning and Teaching Grant, Centre for the Support and Advancement of Learning and Teaching (C-SALT), University of the Sunshine Coast, Grant no. EnhLTG2013/01.

\section{References}

[1] N. Patel, "Automation in hematology: Here's the state of the art in 2014," Medical Laboratory Observer, vol. 46, pp. 6-11, 2014.

[2] R. L. Drake, J. M. McBride, N. Lachman, and W. Pawlina, "Medical education in the anatomical sciences: the winds of change continue to blow," Anatomical Sciences Education, vol. 2, no. 6, pp. 253-259, 2009.

[3] A. R. Thompson and D. J. Lowrie, "An evaluation of outcomes following the replacement of traditional histology laboratories with self-study modules," Anatomical Sciences Education, vol. 10, no. 3, pp. 276-285, 2017.

[4] D. Gruner, K. Pottie, D. Archibald et al., "Introducing global health into the undergraduate medical school curriculum using an e-learning program: A mixed method pilot study Approaches to teaching and learning," BMC Medical Education, vol. 15, no. 1, article no. 142, 2015.

[5] A. Salajegheh, A. Jahangiri, E. Dolan-Evans, and S. Pakneshan, "A combination of traditional learning and e-learning can be more effective on radiological interpretation skills in medical students: A pre- and post-intervention study Approaches to teaching and learning," BMC Medical Education, vol. 16, no. 1, article no. 46, 2016.

[6] D. A. Back, F. Behringer, T. Harms, J. Plener, K. Sostmann, and H. Peters, "Survey of e-learning implementation and faculty support strategies in a cluster of mid-European medical schools," BMC Medical Education, vol. 15, no. 1, article no. 420, 2015.

[7] S. M. Salter, A. Karia, F. M. Sanfilippo, and R. M. Clifford, "Effectiveness of E-learning in pharmacy education," American Journal of Pharmaceutical Education, vol. 78, no. 4, article no. 83, 2014.

[8] F. R. Dee, "Virtual microscopy in pathology education," Human Pathology, vol. 40, no. 8, pp. 1112-1121, 2009.
[9] P. W. Hamilton, Y. Wang, and S. J. McCullough, "Virtual microscopy and digital pathology in training and education," APMIS, vol. 120, no. 4, pp. 305-315, 2012.

[10] G. M. Velan, P. Jones, H. P. McNeil, and R. K. Kumar, "Integrated online formative assessments in the biomedical sciences for medical students: Benefits for learning," BMC Medical Education, vol. 8, article no. 52, 2008.

[11] C. H. Mayfield, P. T. Ohara, and P. S. O’Sullivan, “Perceptions of a mobile technology on learning strategies in the anatomy laboratory," Anatomical Sciences Education, vol. 6, no. 2, pp. 8189, 2013.

[12] F. E. Craig, J. B. McGee, J. F. Mahoney, and C. G. Roth, “The Virtual Pathology Instructor: A medical student teaching tool developed using patient simulator software," Human Pathology, vol. 45, no. 10, pp. 1985-1994, 2014.

[13] F. Sendra-Portero, O. E. Torales-Chaparro, and M. J. RuizGómez, "Medical students' skills in image interpretation before and after training: A comparison between 3rd-year and 6thyear students from two different medical curricula," European Journal of Radiology, vol. 81, no. 12, pp. 3931-3935, 2012.

[14] B. L. Olson and J. L. McDonald, "Influence of online formative assessment upon student learning in biomedical science courses," Journal of Dental Education, vol. 68, no. 6, pp. 656659, 2004.

[15] Y. Morgulis, R. K. Kumar, R. Lindeman, and G. M. Velan, "Impact on learning of an e-learning module on leukaemia: A randomised controlled trial," BMC Medical Education, vol. 12, no. 1, article no. 36, 2012.

[16] D. A. Cook, A. J. Levinson, S. Garside, D. M. Dupras, P. J. Erwin, and V. M. Montori, "Instructional design variations in internetbased learning for health professions education: a systematic review and meta-analysis," Academic Medicine, vol. 85, no. 5, pp. 909-922, 2010.

[17] P. Polly, N. Marcus, D. Maguire, Z. Belinson, and G. M. Velan, "Evaluation of an adaptive virtual laboratory environment using Western Blotting for diagnosis of disease," BMC medical education, vol. 14, p. 222, 2014.

[18] Smart Sparrow, "Adaptive eLearning Platform," 2016, Smart Sparrow Pty Ltd., Sydney, NSW, Australia. https://www.smartsparrow.com/.

[19] I. Chubb, "Opening address to the National Forum on Education in the Biomedical Sciences," National Forum on Education in the Biomedical Sciences. Canberra, ACT, Australia; 2011, Australian Academy of Science, http://www.chiefscientist.gov.au/wp-content/uploads/National-Forum-on-Education-in-the-Biomedical-Sciences-_2_.pdf.

[20] R. Baker, E. Matulich, and R. Papp, "Teach Me In The Way I Learn: Education And The Internet Generation," Journal of College Teaching \& Learning (TLC), vol. 4, no. 4, pp. 27-32, 2011.

[21] V. Shute and B. Towle, "Adaptive e-learning," Educational Psychologist, vol. 38, no. 2, pp. 105-114, 2003.

[22] S. Krasne, P. F. Wimmers, A. Relan, and T. A. Drake, "Differential effects of two types of formative assessment in predicting performance of first-year medical students," Advances in Health Sciences Education, vol. 11, no. 2, pp. 155-171, 2006.

[23] E. O’Neill, N. T. Stevens, E. Clarke, P. Cox, B. O’Malley, and H. Humphreys, "Use of e-learning to enhance medical students' understanding and knowledge of healthcare-associated infection prevention and control," Journal of Hospital Infection, vol. 79, no. 4, pp. 368-370, 2011.

[24] M. R. Davids, U. M. E. Chikte, and M. L. Halperin, "An efficient approach to improve the usability of e-learning resources: The 
role of heuristic evaluation," American Journal of Physiology Advances in Physiology Education, vol. 37, no. 3, pp. 242-248, 2013.

[25] H. Mohammadi, "Investigating users' perspectives on elearning: An integration of TAM and IS success model," Computers in Human Behavior, vol. 45, pp. 359-374, 2015.

[26] G. B. Prusty, C. Russell, R. Ford et al., "Adaptive tutorials to target threshold concepts in mechanics - A community of practice approach," in Proceedings of the 2011 Australasian Association for Engineering Education Conference (AAEE 2011), pp. 305-311, Australasian Association for Engineering Education, Australia, 2011.

[27] C. R. Davis, A. S. Bates, H. Ellis, and A. M. Roberts, "Human anatomy: Let the students tell us how to teach," Anatomical Sciences Education, vol. 7, no. 4, pp. 262-272, 2014.

[28] M. M. Waldrop, "Education online: The virtual lab," Nature, vol. 499, no. 7458, pp. 268-270, 2013. 


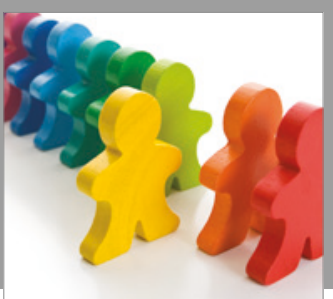

Autism

Research and Treatment
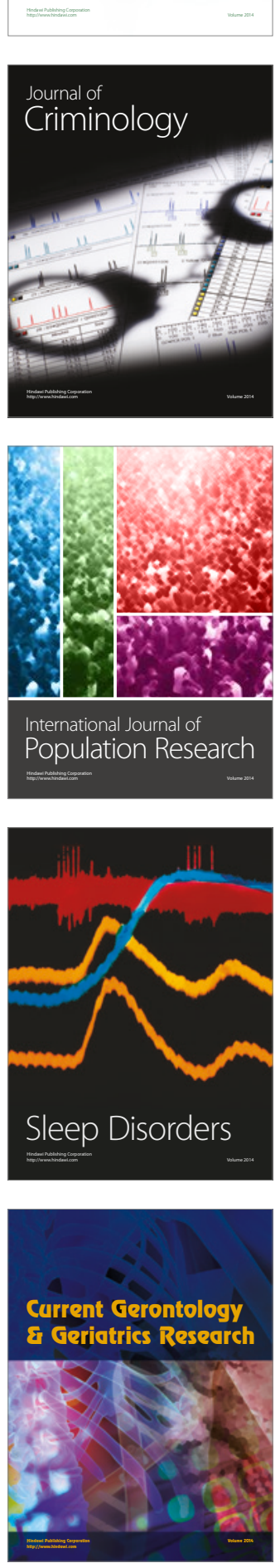

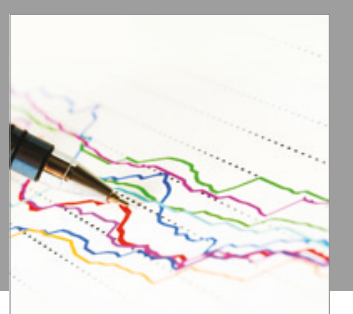

Economics

Research International

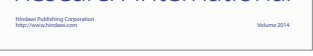

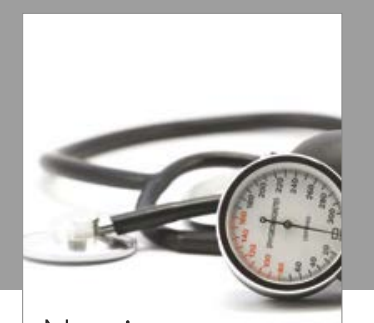

Nursing

Research and Practice

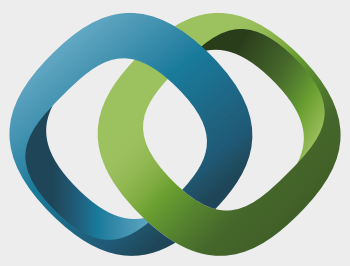

\section{Hindawi}

Submit your manuscripts at

https://www.hindawi.com
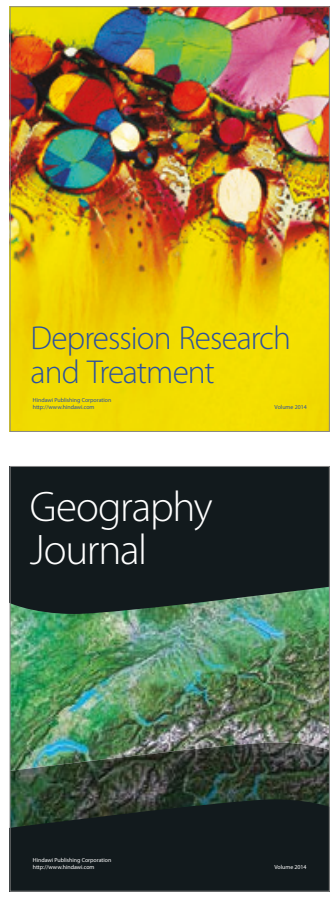
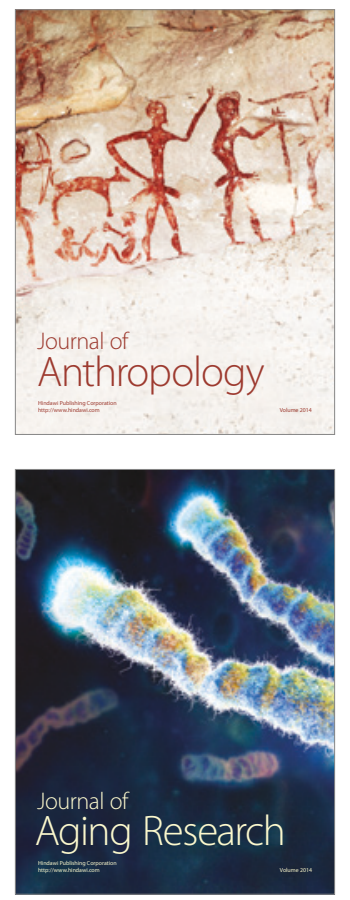
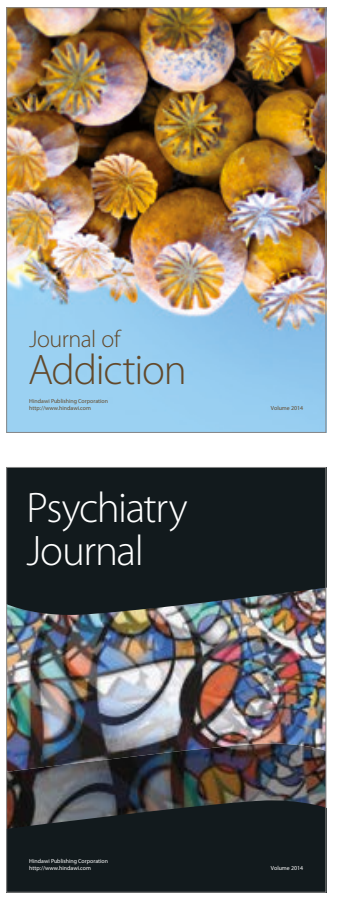

Child Development

Research

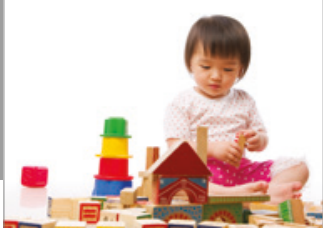

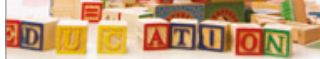
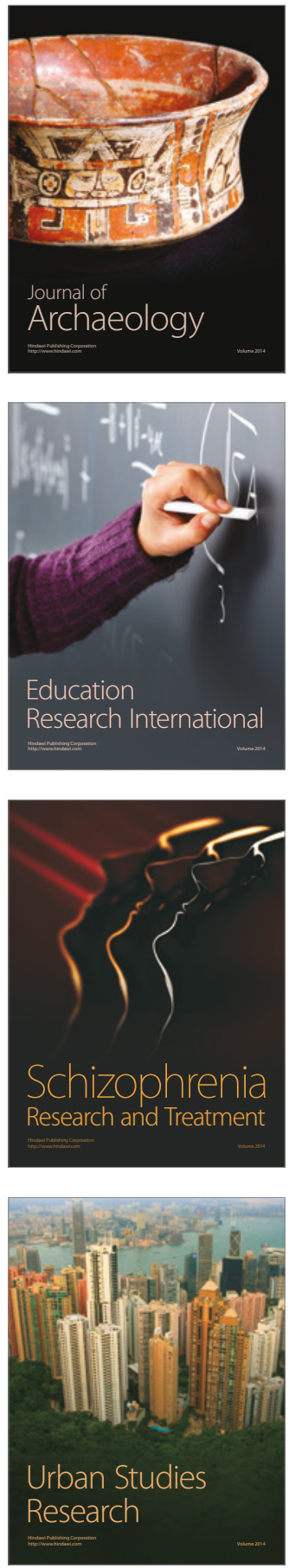